\title{
Indications for Surgical Removal of the Eye in Irrua, Nigeria
}

\author{
ME Enock, ${ }^{1}$ AE Omoti, ${ }^{2}$ UC Fuh, ${ }^{1}$ AA Alikah ${ }^{1}$ \\ ${ }^{1}$ Irrua Specialist Teaching Hospital, Irrua, Edo State , Nigeria \\ ${ }^{2}$ University of Benin Teaching Hospital, Benin City, Edo State, Nigeria
}

\section{SUMMARY}

Objective: To determine the reasons for removal of the eye at the Irrua Specialist Teaching hospital, Irrua, Edo State, southern Nigeria.

Method: A retrospective study of all cases of enucleation and evisceration carried out over a 10-year period - July 1997 to June 2007 - at the Irrua Specialist Teaching Hospital. Data from theatre records and case notes were analysed with respect to age, sex, interval between onset of symptoms and presentation, indications for surgery and type of surgery done.

Results: A total of 42 patients had enucleation or evisceration during the period, accounting for $6.96 \%$ of all ophthalmic surgeries (603) over the same period. Eight eyes were enucleated (19.05\%) and 34 eyes were eviscerated (80.95\%). There were 21 males (50\%) and 21 females (50\%). The most common reason for removal of the eye was a ruptured globe secondary to severe ocular trauma $(35.71 \%)$. This was followed by panophthalmitis $(26.19 \%)$ and intraocular tumours $(9.52 \%)$. Forty patients (95.2\%) presented after one week of onset of ocular lesions; 20(47.6\%) had used traditional eye medication, and $4(9.5 \%)$ had used eye drops containing corticosteroids.

Conclusion: Health education programmes aimed at increasing public awareness on dangers of self medication, the use of native medication and the need to present early to hospital are highly recommended. Also, protective goggles and helmets with plastic facial coverings are recommended for workers who are at risk for eye trauma.

Key words: eye, enucleation, evisceration, Nigeria

\section{INTRODUCTION}

When an eyeball is removed, the effect is not only uniocular blindness, but there is also a cosmetic blemish with associated negative effects on the psychological and physical state of that individual. Usually, removal of the eyeball is resorted to only when an eyeball or vision can no longer be salvaged.
There are three methods of removal of the eyeball. First is evisceration, which is removal of the intraocular contents leaving only the scleral shell. The second method is enucleation which involves the removal of the whole intact eye by cutting the six extra-ocular muscles and transecting the optic nerve. The third is exenteration, which is removal of the entire orbital contents down to the bone. It is a mutilating operation and is only indicated in the treatment of extensive malignant tumours in the orbit. Exenteration is, however, no longer popular due to availability of radiotherapy.

Previous similar studies in Ibadan and Benin City showed that infection, trauma and tumours were the major reasons for the removal of the eyeball. ${ }^{1,2}$ In Gambia, infection, staphyloma and tumours were the commonest causes. ${ }^{3}$ However, in Lagos, tumours, chronic inflammatory diseases and painful blind eye secondary to glaucoma were found to be the commonest reasons for enucleation. ${ }^{4}$ In Sagamu, trauma, panophthalmitis and malignant tumours were the most common causes; ${ }^{5}$ whereas in Onitsha, infections, trauma and tumours were the commonest causes. $^{6}$ In other developing countries, tumours and trauma were the most common indications for destructive eye surgery. ${ }^{7-9}$ In developed countries, on the other hand, tumours and painful blind eyes were the most frequent causes..$^{10-13}$

Most of the events leading to removal of the eyeball are preventable. This study reviews the reasons for enucleation and evisceration at the Irrua Specialist Teaching Hospital, Irrua, a sub-urban tertiary health institution of Edo State, Nigeria, over a ten-year period (July 1997 - June 2007) and to compare the findings with other hospitals in Nigeria and elsewhere.

\section{PATIENTS AND METHODS}

The case notes of all the patients who had an eye removed at Irrua Specialist Hospital during the 10-year study period were retrieved and information on age, gender, diagnosis, interval between onset of symptoms and presentation, use of traditional medication or self medication and modality of treatment were recorded. The results were analysed using the

${ }^{*}$ Correspondence: Dr. ME Enock, Irrua Specialist Teaching Hospital, Irrua, Edo State , Nigeria; E-mail: pstdrmalachi@yahoo.com 
EPI-INFO version 6 software. Discrete variables were expressed as percentages and displayed on frequency tables.

\section{RESULTS}

A total of 42 patients had enucleation or evisceration during the study period. This accounted for $6.97 \%$ of the total number of ophthalmic surgeries (603) performed during the period. Eight eyes were enucleated (19.05\%) and 34 eyes were eviscerated (80.95\%). There were 21 males $(50 \%)$ and 21 females $(50 \%)$. Table 1 shows the age and sex distribution of the patients. Eleven patients $(26.2 \%)$ were between $71-80$ years and 5 patients $(11.9 \%)$ were aged 10 years and below.

Table 1. Age and sex distribution of patients

\begin{tabular}{lcccc}
\hline $\begin{array}{l}\text { Age } \\
\text { (years) }\end{array}$ & Male & Female & Total & \% Frequency \\
\hline$<10$ & 3 & 2 & 5 & 11.9 \\
$11-20$ & 3 & 1 & 4 & 9.5 \\
$21-30$ & 1 & 2 & 3 & 7.1 \\
$31-40$ & 2 & 2 & 4 & 9.5 \\
$41-50$ & 3 & 3 & 6 & 14.3 \\
$51-60$ & 1 & 3 & 4 & 9.5 \\
$61-70$ & 3 & 2 & 5 & 11.9 \\
$71-80$ & 5 & 6 & 11 & 26.2 \\
Total & 21 & 21 & 42 & 100.0 \\
\hline
\end{tabular}

Table 2 shows the reasons for enucleation and evisceration. Fifteen eyes (35.7\%) were removed due to a ruptured globe secondary to severe ocular injury (trauma). This was followed by panophthalmitis with 11 eyes (21.19\%).

Table 3 shows the yearly distribution of enucleation and evisceration carried out over the period. There was an average of 3 surgeries per year between 1997 and 2002. This doubled to 6 surgeries per annum between 2003 and 2007.

Table 2. Causes of enucleation or evisceration

\begin{tabular}{lcccc}
\hline Causes & Enucleation & Evisceration & Total & $\begin{array}{c}\text { Frequency } \\
\%\end{array}$ \\
\hline $\begin{array}{l}\text { Ruptured globe } \\
\text { (trauma) }\end{array}$ & 1 & 14 & 15 & 35.7 \\
$\begin{array}{l}\text { Panophthalmitis/ } \\
\text { Endophthalmitis }\end{array}$ & 0 & 11 & 11 & 26.2 \\
$\begin{array}{l}\text { Intraocular } \\
\text { tumours }\end{array}$ & 4 & 0 & 4 & 9.5 \\
Staphyloma & 0 & 4 & 4 & 9.5 \\
Painful blind eye & 2 & 2 & 4 & 9.5 \\
Phthisis bulbi & 1 & 3 & 4 & 9.5 \\
Total & 8 & 34 & 42 & 100.0 \\
\hline
\end{tabular}

Table 3. Yearly distributions of enucleation and evisceration

\begin{tabular}{ccc}
\hline Year & Number of Surgeries & \% Frequency \\
\hline 1 & 1 & 2.39 \\
2 & 3 & 7.1 \\
3 & 2 & 4.76 \\
4 & 4 & 9.52 \\
5 & 3 & 7.14 \\
6 & 4 & 9.52 \\
7 & 5 & 11.90 \\
8 & 5 & 11.90 \\
9 & 8 & 19.04 \\
10 & 7 & 16.67 \\
\hline Total & 42 & 100.0 \\
\hline
\end{tabular}

Twenty patients (47.6\%) comprising of 12 males and 8 females had used traditional eye medication (TEM) prior to presentation. Also, 4 patients $(9.5 \%)-3$ males and 1 female had used eye drops containing steroids prior to presentation.

One patient $(2.4 \%)$, a child presented with endophthalmitis secondary to a broomstick injury at school. Seven patients $(16.7 \%)$, all above 60 years, had mild ocular trauma on the farm which progressed to panophthalmitis.

Two patients (4.8\%) presented within one week of onset of symptoms of the disease process, but with severe panophthalmitis and visual loss. Twenty-six patients $(61.9 \%)$ presented between one week and one month of the disease process, while fourteen patients $(33.3 \%)$ presented between two months to several years of the injury or disease onset.

\section{DISCUSSION}

The decision to remove an eyeball is usually a difficult one for both the surgeon and the patient. ${ }^{3}$ Hence, it is the last option for the surgeon and the patient when all other efforts to salvage the eye have failed. For the patient, the loss is enormous since any form of artificial replacement of the organ is usually functionless (vision wise). At best, an improved cosmetic appearance is all that is achieved. ${ }^{3}$

The most common reason for removal of the eye in this study was trauma (35.71\%). This was followed by panophthalmitis $(26.19 \%)$ and then intraocular tumours $(9.52 \%)$. This trend is similar to a study done at Sagamu, in which trauma, panophthalmitis and malignant tumours were found to be the most common indications for destructive eye surgery. ${ }^{5}$ Trauma was also the leading cause for the removal of the eye in other previous similar studies. $8,9,14,15$

Severe perforating ocular injury with visual loss was the most important reason for eye removal in this study. This could be due to the fact that the Irrua Specialist Teaching Hospital, which is situated along the very busy Benin-Abuja highway, is the nearest and most easily accessible tertiary 
hospital for road traffic accident victims in that area (Edo central, Edo north and parts of Ondo and Kogi states). Also, motorcycle-related road traffic accidents are an important cause of ocular injury in the environment. This is due to the fact that students of Ambrose Alli University, which is just about $5 \mathrm{~km}$ from Irrua, use motorcycles as means of transport to and from their hostels. It was observed that motorcyclerelated ocular injury is an important cause of ocular morbidity in Irrua. ${ }^{16}$ Panophthalmitis was the next most frequentlyfound reason for removal of the eye in this study. In some other studies, however, it was the commonest reason for removal of the eye. ${ }^{1-3,6}$ It appears to be the end-stage of a process which may have started out as a minor trauma, or from the use of traditional eye medication (TEM), or from delayed treatment of minor conditions such as conjunctivitis. ${ }^{3}$ The use of TEM contributed in no small measure to the disastrous outcome of some of the eyes. ${ }^{3,6}$ Irrua, though a suburban community, is still largely rural in terms of development, hence traditional eye healers abound. Mild ocular trauma, which could have healed easily with adequate treatment, will eventually progress to corneal ulcers and then panophthalmitis due to the harmful effects of traditional eye medication. Loss of the eye from panophthalmitis, following the use of harmful traditional eye medicines, has been documented. . $^{2,6,6}$

Also, some patent medicine dealers dispense steroid eye drops to patients with mild corneal abrasion which may progress to ulceration and panophthalmitis. This was highlighted in a previous study in Onitsha. ${ }^{6}$ In the present study, four of the eleven cases of panophthalmitis admitted to having used steroid eye drops after mild ocular trauma. Incidentally, three of the patients were given the steroid drops by an optician practicing in a nearby town.

The causes of mild ocular trauma progressing to panophthalmitis due to the harmful effect of traditional eye medication or steroids as seen in this study include, broom stick injury in a child and injuries sustained while working on the farm. Mild injuries sustained during farm work were the causes of seven cases of panophthalmitis in the patients above 60 years of age. Such elderly people in the environment of this study rely strongly on traditional eye medication and will usually use them before presentation, by which time panophthalmitis would have set in.

Intraocular tumours, staphyloma, painful blind eye and phthisis bulbi were the other reasons for removal of the eye in this study.

Retinoblastoma was the main intraocular tumour that necessitated removal of the eye in this study. All cased were found in children below the age of 10 years. Two of these presented early with a 'cat's eye reflex and are still alive till today. Retinoblastoma was also the most common intraocular tumour in previous similar studies. ${ }^{1-4,7,10,11,12}$
In patients with staphyloma, the eyes were removed for cosmetic reasons. Two of these cases were due to trauma that occurred some years earlier when the patients were young. This is similar to the findings by the study in India. ${ }^{7}$ The other two admitted to having had an eye infection when they were also young. This infection could be due to measles. However, measles is no longer a common cause of staphyloma as shown by an earlier study, due to the impact of the National Programme on Immunization. ${ }^{2}$

Of the four painful blind eyes that were removed were removed, three were due to intractable glaucoma. The cause in the fourth case was ocular trauma many years prior to presentation.

Eyes were removed in four cases of phthisis bulbi for cosmetic reasons. Previous trauma was the cause of the phthisis bulbi.

The male to female ratio of 1:1 in this study is similar to the study in Zaire that had a male: female ratio of 1.2:1.

More surgeries were carried out in the last four years due to the presence of a full-time consultant ophthalmologist. The first 6 years recorded lower surgical output because the hospital only had two visiting ophthalmologists who ran clinics twice a week. The presence of a full-time ophthalmologist has attracted more referrals.

In conclusion, most of the reasons for the removal of the eye in this study were preventable. Public heath enlightenment campaigns need to be intensified by the primary health departments of the local government in order to educate the rural populace on the need to present early to hospital, and on the harmful effects of traditional eye medications (TEM). School health programmes should lay more emphasis on eye health. Close supervision of children at home and at school when playing to prevent them sustaining eye injuries cannot be overemphasized. Government, as a matter of urgency, should enact a law to prevent advertisement by traditional eye healers. In addition, government should also fine/punish reckless motorists and ensure that the roads are in good condition. Protective goggles or helmets with plastic facial coverings are recommended for people at risk of ocular injury, such as farmers and motorcycle riders.

\section{ACKNOWLEDGEMENT}

We wish to acknowledge the secretarial assistance of Miss Vivian Iyoha for the typesetting of the manuscript.

\section{REFERENCES}

1. Baiyeroju-Agbeja AM, Ajibade HA. Causes of removal of the eye in Ibadan. Nig J Surg 1996; 30: 33-40. 
2. Ukponmwan $\mathrm{CU}$, Enock M. Enucleation and evisceration in Benin-City. Nig J Surg 1998; 5: 16-9.

3. Dawodu OA, Hannah BF. Enucleation and evisceration in the Gambia . Nigerian Journal of Ophthalmology 2000; 8(1): 29-33.

4. Majekodunmi S. Causes of enucleation of the eye at Lagos University Teaching Hospital: A study of 101 eyes. West Afr J Med 1989; 8: 288-91.

5. Bodunde OT, Ajibode HA, Awodein OG. Destructive eye surgeries in Sagamu. Nigerian Medical Practitioner 2005; 48:47-9.

6. Nwosu SN. Destructive ophthalmic surgical procedures in Onitsha. Niger Postgrad Med J 2005; 12(1): 53-6.

7. Vemuganti GK, Jalali S, Honavan SG, Shekar GC. Enucleation in a tertiary eye care centre in India: Prevalence, current indications and clinicopathological correlation. Eye 2001; 15: 760-5.

8. Viviane RC, Ana Christina CN, Sigmar De Mello R. Evaluation of the aetiology of ocular globe atrophy or loss. Braz Dent $J$ 2005; 16(3): 103-6.

9. Kaimbo K. Causes of enucleation in Zaire. J Fr Ophthalmol 1988; 11(10): $677-80$.

10. Shield CL, Sheild JA, De Potter P, Singh AD. Problems with
Indications for Surgical Removal of the Eye in Irrua, Nigeria

hydroxyapatite orbital implant experience with 250 consecutive cases. Br J Ophthalmol 1994; 78: 706.

11. Batten KL. Causes of enucleation as seen in Jerusalem. $\mathrm{Br} J$ Ophthalmol 1971; 55: 174-6.

12. Lim JKS, Cinotti AA. Cause for removal of the eye: A study of 890 eyes. Annals of Ophthalmol 1976; 8: 865-9.

13. Anna SK, Amy LW, Christine ML, Helmat B, Diva RS. Clinicopathologic correlations in 646 consecutive surgical eye specimens 1990-2000. Am J Clin Path 2003; 119(4): 594-601.

14. Schien OD, Hibbered PL, Shingleton BJ, et al. The spectrum and burden of ocular injury. Ophthalmology 1988; 95: 300-5.

15. Mc Ewen J. Eye injuries: A prospective survey of 5671 cases. $\mathrm{Br}$ J Ophthalmol 1989; 73: 888-94.

16. Enock ME, Omoti AE, Alikah AA. Risk factors identification for ocular trauma in patients who presented in suburban tertiary care hospital in Nigeria. Saudi Med J 2007; 28(9): 1385-8.

17. Osahon AO. Consequences of traditional eye medication in UBTH, Benin City. Nigerian Journal of Ophthalmology 1995; 3:514 . 